\title{
DESINFORMAÇÃO E CONFORMISMO NA ÁREA DE SAÚDE: O CASO DE BELO HORIZONTE
}

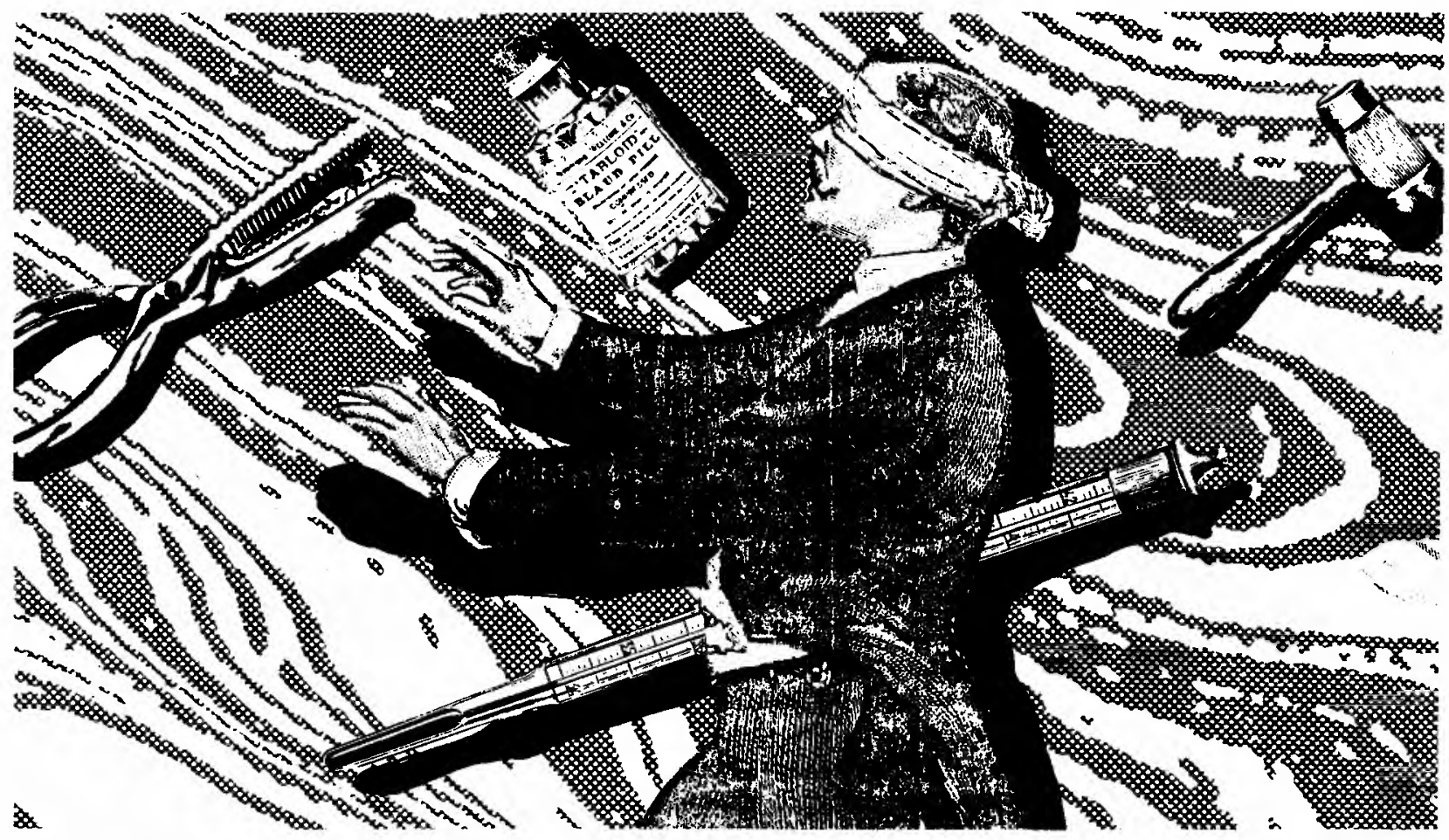

\section{- ADELAIDE MARIA COELHO BAÊta}

Professora Adjunta do Curso de Mestrado em Administração da Universidade Federal de Minas Gerais.

$F$ ste texto objetiva questionar o papel dos agentes e profissionais de saúde na determinação da trajetória do paciente na rede hierarquizada dos serviços de saúde.

Levando-se em conta a organização dos serviços proposta pelo Sistema Nacional de Saúde, Lei $6.229 / 75$, e as condições de saúde da população brasileira, procurou-se responder a algumas indagações acerca das razões por que a população, de modo geral, não se sente no direito de exigir atenção adequada, mesmo sendo ela a financiadora do sistema.
O trabalho é uma análise da atuação dos profissionais na organização dos serviços de assistência médica em Belo Horizonte, no que diz respeito à prestação de informações que orientam o paciente dentro da rede de prestação de serviços de saúde.

Como fonte inicial de dados, foram utilizados os documentos legais sobre o Sistema Nacional de Saúde e outros que se referem à estruturação dos serviços de assistência médica.

Os dados empíricos foram obtidos na pesquisa sobre Hierarquização dos Serviços de Saúde, realizada em 1984, considerando-se como universo de estudo os hospitais gerais pediátricos $\mathrm{e}$ de adultos, envolvendo uma amostra de 31 hospitais. Foram entrevistados pacientes, diretores clínicos, chefes administrativos, chefes de enfermagem, através de questionários diferenciados segundo a categoria analisada. 
Definiu-se como objeto de estudo a trajetória dos pacientes ao serem atendidos na rede hospitalar de Belo Horizonte. Foram utilizados dados do prontuário médico dos pacientes para a reconstrução da sua trajetória, além das entrevistas com os pacientes e com as chefias dos hospitais.

A alternativa de reconstruir a trajetória do paciente na Organização dos Serviços de Saúde deve-se a que o Sistema Nacional de Saúde, criado pela Lei $6.229 / 75$, supõe a montagem de uma estrutura integral hierarquizada e regionalizada, i.e., uma rede que integra os serviços de atendimento à saúde, partindo das açőes mais simples (ambulatorial e preventiva) às ações mais complexas (atendimento hospitalar), que envolvem a utilização em maior grau de medicamentos e equipamentos. Tais serviços são distribuídos geograficamente numa região no sentido periferia-centro, por níveis de complexidade crescente.

O hospital se encontra nos níveis mais altos dessa estrutura hierar̀quizada, uma vez que está capacitado a atender os casos de cuidados mais intensivos, que exigem recursos mais complexos.

Por isso mesmo, os pacientes em alta hospitalar atingiram a etapa final na hierarquia dos serviços e deveriam se encontrar em posição de visualizar a rede como um todo.

Dentro da complexidade de aspectos que envolvem as questōes de saúde, pode-se destacar a assistência médica como um dos pontos de importância para a compreensão dos mecanismos que interferem diretamente na saúde do brasileiro.

O problema da assistência à saúde é abordado, geralmente, de duas perspectivas diferentes: uma técnica e outra política.

Do ponto de vista técnico, tem sido enfatizada a necessidade de racionalização dos recursos a fim de estender a assistência médica a um maior número de pessoas (ampliação da cobertura).

Já a questão política relaciona-se ao reconhecimento da saúde como direito do cidadão e dever do Estado.

Segundo os especialistas no assunto, a crescente demanda por serviços assistenciais e as mudanças nos padrões de morbidade, aliadas ao aumento significativo dos custos e à escassez relativa de recursos, vêm impondo uma forte preocupação com a eficácia e eficiência dos serviços.

A ênfase no melhor aproveitamento dos recursos disponíveis, através de uma maior racionalização em sua distribuição e utilização, tem ganho força e consenso entre os planejadores de saúde. Os princípios de hierarquização dos serviços são apontados como forma de viabilizar tal racionalização.

O modelo de atendimento à saúde, adotado a partir da Lei $6.229 / 75$, que instituiu o Sistema Nacional de Saúde, busca eliminar a divisão entre a medicina preventiva e curativa que vigorava no modelo anterior, através da criação de uma rede única de atendimento que integra as ações preventivas e curativas. A estruturação dos serviços de saúde, conforme o disposto na Lei 6.229 , decorre da tendência crescente em escala mundial de se organizarem os serviços de saúde de forma mais eficiente, mais eficaz, evitando-se a proliferação desenfreada dos serviços. Essa tendência revela também uma participação crescente do Estado na organização e na distribuição dos serviços de assistência médica (1). Tal estrutura obedece às normas da Organização Mundial de Saúde (O.M.S.), e, conforme dissemos mais acima, organiza a assistência médica por níveis de atenção, hierarquizados segundo a complexidade e intensidade do cuidado, distribuídos regionalmente no sentido periferiacentro por graus de complexidade crescente de recursos. Vale dizer que os recursos são distribuídos conforme o grau de complexidade e da intensidade do cuidado requerido. São três os níveis de cuidado: primário, secundário e terciário, configurando atividades específicas.

Embora caracterizados por atividades diferentes, esses três níveis de cuidado não se excluem, ao contrário, se completam e suas atividades devem ser necessariamente integradas.

De acordo com a lei, todos os ministérios incluídos no sistema devem "elaborar programas regionais observando sempre a necessária participação de todos os órgāos públicos e privados que atuam na região, de modo a organizá-la segundo hierarquia técnica condizente com a área assistida $e$ os pontos de convergência para o atendimento de riscos especiais" (2).

O Sistema Nacional de Saúde, ao propor a reorganização dos serviços de atenção à saúde numa rede única de atendimento integrando os esforços da medicina preventiva e curativa, através da hierarquização e regionalização dos serviços, pressupõe a dinamização e ampliação dos serviços de atenção primária como forma de ajustar a demanda aos níveis mais complexos, evitando-se os gastos desnecessários com a medicina curativa.

1. CHAVES, Mário M. Sauide e Sistemas. Rio de Janeiro, Fundação Getúlio Vargas, 1978.

2. REPÚBLICA FEDERATIVA DO BRASIL. Diário Oficial. Brasília- DF, 18/jul/1975. 
Essa lei, nas palavras de Marton, "apesar de não lograr a eliminação das distorçôes, favorece o aparecimento de programas experimentais que procuram modelos alternativos de organização dos serviços. Os programas de extensão da cobertura, com pressupostos de medicina comunitária, abrem um espaço para o seu desenvolvimento, com o aval dos órgáos oficiais responsáveis pela política de saúde" (3).

Surgem, então, programas com ênfase na descentralização das decisð̃es, participação da comunidade, integração entre açôes preventivas e curativas e regionalização dos serviços, entre eles o Programa de Interiorização de Açóes de Saúde e Saneamento (PIASS) e o Programa Nacional de Servicos Básicos de Saúde (PREVSAÚDE) em 1980, e, mais recentemente, o Programa de Açres Integradas de Saúde (AIS).

O desenvolvimento dos dois primeiros programas, conquanto não tenham eles passado de projetos experimentais, contribuiu para apontar as dificuldades na operacionalização do sistema, sobretudo no que diz respeito à integração dos serviços e à sistematização da demanda.

A adoção do modelo sistêmico na organização dos serviços de saúde significou um passo adiante na própria concepção de saúde, uma vez que encara as medidas curativas como complementares ou secundárias à atenção primária. Isto supõe a transposição dos limites de um conceito restrito de saúde, puramente biológico, que vê a saúde como simples ausência de enfermidade, em direção a um conceito mais amplo que entende a saúde como um estado de equilíbrio com o meio, ou, nas palavras de Luz, "como um conceito que ultrapassa a medicalização preventiva ou curativa $e$ inclui as condiçôes de vida globais em uma sociedade" (4).

A grande importância de se enfocarem as açōes de saúde como sistema deriva do fato de serem elas integradas à busca do objetivo comum, ou seja, a manutenção da saúde da população.

"Para evitar a tradicional justaposição e duplicação de serviços que a divisdo estanque de trabalho tem produzido na saúde, o Sistema $\mathrm{Na-}$ cional de Saúde tenta prever a implantação de serviços municipais, com ações médicas hierarquizadas, segundo graus de sofisticação, tecnologia, abrindo espaço para uma atençăo médica primária generalista, mais de acordo com as necessidades médicas imediatas de grande parte da população brasileira" (5).

Entretanto, as análises recentes sobre a atuação do Sistema Nacional de Saúde têm demonstrado a fragilidade da administração pública em coordenar efetivamente o sistema, de modo a promover a utilização adequada dos recursos em função das necessidades da populaçăo.

Se, por um lado, a criação do Sistema Nacional de Saúde é um salto qualitativo na colocação dos problemas de saúde, na medida em que pressupõe a troca de influências entre o sistema e a populaçăo, por outro lado, é possível que a montagem de uma estrutura hierarquizada que não leve em conta aspectos culturais e funcionais de acessibilidade aos serviços acabe por manter a situação e não por mudá-la.

A esse respeito, afirma Gentille de Mello (6) que "a Lei 6.229, ao que tudo indica, pretendeu delimitar as areas de atuação de cada órgdo $e$ cada entidade componente da estrutura sanitária", de tal forma "que se anulem a competição, as rivalidades $e$ as lutas entre instituiçסes que prestam serviços de saúde" . E mais adiante diz ele: "Não constituiu surpresa, para os que trabalham no setor, o fato significativo de que, decorrido um ano de vigência da Lei 6.229, não haja sinais de alteraçôes substanciais no sistema, que prossegue incoordenado e caótico" (7).

Do ponto de vista administrativo, a abordagem sistêmica representou relativo avanço, na medida em que possibilitou não apenas a análise relacional das várias partes da organização, mas também e principalmente porque permitiu relacionar a organizaçăo e o ambiente. Considerando as influências recíprocas, estabelece como condição de eficácia o feedback, isto é, a comunicação entre o ambiente e o sistema.

Desse modo, o Sistema de Saúde não pode prescindir de mecanismos que realizem essa troca de informaçōes, ou seja, de um eficiente processo de informação para garantir o equilíbrio (homeostase) entre as partes do sistema e adaptá-lo às exigências da realidade. Admite-se que os sistemas têm uma tendência a se adaptarem, a fim de alcançarem um equilíbrio interno face à mudança do ambiente ${ }^{(8)}$. Contu-

3. MARTON, A.M. et alii. "Realização dos serviços de saúde no Brasil". In: Revista de Administração Pública, Rio de Janeiro, Fundaçăo Getúlio Vargas, vol. 17, $\mathrm{n}^{\mathrm{Q}} 3$; jul/set., 1983, pp. 121-149.

4. LUZ, Madel Terezinha. As Instituições Médicas no Brasil. Rio de Janeiro, Graal, 1979, p. 164.

5. Idem, ibidem, p. 163.

6. GENTILLE DE MELLO, Carlos. Saúde e assistenncia médica no Brasil. São Paulo, CEBES-HUCITEC, 1977, p. 193.

7. Idem, ibidem, idem.

8. BERTALANFFY, Ludwig von. General systems theory. New York, George Brasilier, 1968. 
do não se podem desconhecer as dificuldades de se concretizar a idéia de sistema "aberto". A prática da análise de sistemas tem revelado uma certa irracionalidade (fechamento) porquanto, na maioria das vezes, o sistema se volta principalmente para a administração de seus conflitos internos, mais do que para questões relacionadas às necessidades e demandas externas.

Neste sentido, pode-se deduzir que a intervenção estatal deveria estimular o processo de informação entre a organização de saúde e a população, como forma de garantir a adequação dos serviços às necessidades da população, à medida que torne público os objetivos e o funcionamento do sistema, reorientando a demanda pelos serviços e favorecendo a fiscalização dos mesmos.

Tomando por suposto que a implantação e operacionalizacão da organização sistêmica dos serviços de saúde é afetada pelas condições que a população tem de se informar e de se expressar dentro da rede de serviços, buscamos conhecer o processo de informação na prática da organização dos serviços em Belo Horizonte. Acreditamos que as conclusões que podem ser tiradas a partir deste caso podem, em princípio, aplicar-se à situação dos serviços de saúde nas demais regiōes metropolitanas brasileiras. Tal suposição decorre do reconhecimento do fato de que o Sistema Nacional de Saúde, com os vícios e virtudes que o caracterizam, funciona basicamente do mesmo modo em todo o país.

\section{RESULTADOS DA PESQUISA ${ }^{(9)}$}

Para conhecer o processo de informação na prática da organização dos serviços de saúde procuramos levantar tipos e agentes de informações a que o paciente tem acesso no processo de atendimento na rede de prestação de serviços em Belo Horizonte.

Os dados da pesquisa demonstraram que a grande maioria, isto é, $80 \%$ da amostra dos pacientes atendidos na rede hospitalar de Belo Horizonte são cobertos pela Previdência Social.

Coerentemente, os dados levantados junto às Chefias dos 31 hospitais constantes da amostra confirmam que a maioria dos hospitais atendem predominantemente os pacientes previdenciários.

Uma vez constatado que a clientela atendida nos hospitais de Belo Horizonte é predominantemente previdenciária de baixa renda, buscouse identificar as razōes do atendimento hospitalar através das variáveis tempo de permanência, diagnóstico, exames e tratamento a que os pacientes se submetem. Esta análise leva em conta que o hospital está equipado preferencialmente para o atendimento de nível secundário.
De acordo com a hieraquia dos serviços, os pacientes hospitalizados são encaminhados àquele serviço.

A associação das variáveis diagnóstico, exames realizados e tempo de permanência no hospital com o elevado percentual de internaçóes na especialidade de clínica médica confirmam que, na grande maioria dos casos, os problemas de saúde apresentados pelos pacientes entrevistados poderiam ser atendidos a nível de cuidado primário, não justificando a utilização dos serviços hospitalares.

Tais constatações evidenciam uma prática incorreta de encaminhamento dos pacientes dentro da rede de serviços e o mau funcionamento do sistema em relação aos objetivos de hierarquização dos serviços em Belo Horizonte.

Considerando que entre os entrevistados a categoria previdenciária concentrou em sua maioria pessoas de baixa renda, pode-se supor que, vivendo em condições precárias de moradia e alimentação, essas pessoas submetam-se à internação mesmo quando não necessitem fazer uso de recursos mais complexos, com vistas aos serviços de hospedagem e relativo conforto, uma vez que, como beneficiárias do seguro social, têm garantido o acesso ao hospital.

Por outro lado, dentre as múltiplas causas da demanda por serviços hospitalares, inclui-se "o interesse de certos profissionais de saúde, especialmente no setor privado, em manter as estruturas funcionando, não somente no que se refere à capacidade instalada, como a equipamentos dispendiosos que necessitam ser utilizados para que possam ser economicamente viáveis. Agrega-se a este quadro a remuneração diferenciada que a tradição, os padrões culturais e a tecnificação da assistência à saúde impuseram entre os cuidados curativos e aqueles que visam à promoção da doença. Por outro lado as circunstâncias que geram a necessidade de cuidados curativos näo raro trazem em si elementos de urgência e dramaticidade, o que faz com que estes sejam supervalorizados pelos agentes de saúde, pelos familiares do doente e pela própria sociedade" (10).

Segundo o mesmo autor, a esse elenco de

9. Os dados da pesquisa se encontram na dissertação de mestrado Rede Hierarquizada de Saúde em Belo Horizonte: mito e desinformaçāo, apresentada ao Departamento de Ciência Política da Faculdade de Ciências Humanas da UFMG em novembro de 1986, de autoria de Adelaide Maria Coelho Baêta.

10. AZEVEDO, A. C. de. "Otimização das açôes de saúde a nível nacional". In: Revista de Administração Pública, Rio de Janeiro, Fundação Getúlio Vargas, vol. 15 , extra, 1981, p.59. 
condições, somam-se aspectos subjetivos que desempenham papel relevante na medida em que podem levar os individuos a simularem condições patológicas, como a enfatizar sintomas, a fim de gozarem de pequenas gratificações sociais, psicológicas e familiares relacionadas com a doença (dispensa de trabalho, comiseração e atenção especial de familiares e pessoal de saúde, entre outras) (11).

Como nos lembra Azevedo "a moderna medicina supertecnificada impōe à sociedade contemporânea um ritmo de desenvolvimento de serviços e padróes de utilização que estão mais relacionados a necessidades intrínsecas do setor do que propriamente d̀s carências reais da populaçāo" (12).

Segundo Rodrigues Filho, "as hospitalizações da população urbana no Brasil aumentaram de uma em cada 18 pessoas, no inicio da década de 70, para uma em cada nove pessoas, no final da mesma década" (13).

Segundo esse autor, a expansão dos atendimentos hospitalares nāo retrata forçosamente necessidades da população, já que a utilização hospitalar está associada à oferta de leitos, que cresceu significativamente nos últimos anos, em decorrência da expansão do seguro social.

Vários estudos têm comprovado a grande influência da disponibilidade de leitos sobre a hospitalização. Shain \& Roemer, nos EUA, concluiram que "Hospital beds that are built tend to be used" (14) e Forsyth \& Logan, na Inglaterra, demonstraram que "the number of beds is the number available" (15).

Também no Brasil, o estudo de Rodrigues Filho (16), no Estado da Paraíba, constatou esta associação de disponibilidade de leitos e utilização hospitalar.

Outros estudos confirmam a existência de internações desnecessárias principalmente na área de clínica médica, "já que as internaçoes de clínica médica não são operacionalmente definidas, a exemplo das internações das clinicas cirúrgicas e obstétricas" (17). Forsyth \& Logan, citados por Rodrigues Filho, evidenciaram que 1/4 dos pacientes de clínica médica hospitalizados na Inglaterra ocupavam leitos desnecessariamente (18); e nos EUA a porcentagem de internações desnecessárias em $1978{ }^{(19)}$ era de $14,3 \%$. Vale mencionar o que diz o médico Jayme Landmann: "Não há propriamente escassez de capital para o setor saúde, mas mau uso" (20).

Em Belo Horizonte, o elevado percentual de internaçōes no setor de clínica médica, com diagnósticos relativamente simples, indica que a organização dos serviços não tem alcançado os objetivos de racionalização dos recursos, tendo em vista o elevado custo do atendimento hospitalar.

Segundo os dados da pesquisa, a prática de hospitalização em Belo Horizonte tem-se realizado indiferentemente ao objetivo de hierarquização previsto pelo sistema.

Essas considerações nos levam a questionar o papel da administração pública na organização dos serviços de saúde. Áo contrário do que se propôs, a intervenção estatal no setor não tem conseguido a integração dos serviços ou a utilização adequada dos mesmos, o que evidencia que não tem logrado, portanto, corrigir as distorções na aplicação dos recursos.

Segundo Rodrigues Filho "a intervenção governamental concentrou-se mais na administração financeira das contribuições previdenciárias, pagas compulsoriamente pelos contribuintes, as quais säo em parte repassadas arbitrariamente para os produtores dos serviços, sem qualquer fiscalização por parte da sociedade" (21).

\section{Idem, ibidem.}

12. Idem, ibidem, p. 59.

13. RODRIGUES FILHO, José. "O mercado de serviços médicos". In: Revista de Administração Pública, Rio de Janeiro, Fundaçăo Getúlio Vargas, vol. 19, $\mathbf{n}^{9}$ 1, jan/mar., 1985, p. 101.

14. SHAIN, M. \& ROEMER, M.I. "Hospital Costs Relate to the Supply of Beds". In: The Modern Hospital, Chicago, Crin Communications, vol. 92, $\mathrm{n}^{2} 4$, 1959, pp. 71-73 apud RODRIGUES FILHO, José, "O mercado de serviços médicos", op. cit., p.102.

15. FORSYTH, L. \& LOGAN, R.F.L. The Demande for Medical Care. London, Oxford University Press, 1960 apud RODRIGUES FILHO, José, "O mercado de serviços médicos", op. cit., p. 102.

16. RODRIGUES FILHO, José. "O INAMPS e a 'eficiência' dos hospitais privados lucrativos". In: $R e$ vista de Administração, Săo Paulo, Instituto de Administração da Faculdade de Economia e Administraçăo da Universidade de Săo Paulo, vol. 18, $\mathrm{n}^{\circ} 4$, 1983, pp. 93-97.

17. RODRIGUES FILHO, José. "O mercado de serviços médicos". Op. cit., p. 102.

18. Idem, ibidem, idem.

19. Conforme: Time. New York, June 12, 1978, p. 9.

20. LANDMANN, Jayme. Evitando a saúde e promovendo a doença. Rio de Janeiro, Achiamé, 1982, p. 22.

21. RODRIGUES FILHO, Jose. "O mercado de serviços médicos". Op. cit., p. 104. 
Não obstante o preço da hospitalizaçăo seja zero para o consumidor no ato do atendimento, este se sente compelido ao consumo, uma vez que pagou antecipadamente, e pretende o meIhor atendimento. Nåo importa o preço, nem a sua real necessidade, e o melhor está sempre associado ao mais sofisticado, pois também o paciente năo escapa ao fascínio pela tecnologia.

Observou-se ainda que os pacientes năo apenas desconhecem as condiçōes da hospitalizaçăo, mas também nem sabem a quem recorrer para obter informações, como constatado em $39,47 \%$ dos casos. Enquanto $37,1 \%$ dos pacientes conhecem os serviços do hospital por experiência própria, isto é, porque já estiveram internados ali anteriormente, $21,9 \%$ consultaram amigos e parentes, nem sempre devidamente esclarecidos para opinarem sobre o assunto.

Diferentemente dos pacientes, as chefias dos hospitais, embora afirmem não saber a quem os pacientes recorrem para obter informaçōes, apontam como a melhor fonte de informaçăo os funcionários do hospital $(83,3 \%)$ e, em segundo lugar, o telefone do INAMPS $(11,1 \%)$.

Náo se constatou esforço algum por parte da organização em prover a populaçẵo de informações sobre o funcionamento do sistema. Há uma despreocupação evidente da organização em orientar o paciente quanto à utilização dos serviços. O paciente parece perceber esta situaçăo e reage ignorando a organizaçăo como fonte de informaçăo.

Indagados como fazem normalmente para obter informação sobre os serviços de saúde, os pacientes apontaram os amigos e parentes como os mais consultados $(28,4 \%)$; outra fonte de informação mais freqüente foi o próprio serviço de saúde $(27,1 \%)$. Dos pesquisados, $16,8 \%$ năo souberam responder à indagaçăo e apenas $6,1 \%$ procuraram simplesmente o hospital mais próximo de seu domicílio.

O que se depreende deste quadro é a indiferença generalizada com relação à transferência de dados sobre o sistema para o usuário. Mesmo nos casos em que o paciente passou por outros serviços antes de chegar ao hospital, não há evidência de que tenha recebido esclarecimento ou orientação sobre os serviços.

Sabendo-se que a organização sistêmica dos serviços de saúde estabelece que o paciente, ao dar entrada no sistema, passa por um posto de saúde ou ambulatório e só então deve ser encaminhado aos níveis superiores, através doprocesso de referência, procuramos identificar quem encaminhou o paciente ao hospital, quais as razões que o levaram àquele hospital e que informaçōes o paciente obteve ao se dirigir a tais serviços.
Pelos dados obtidos, $44,9 \%$ dos pacientes internados passaram antes por um posto de saúde ou consultório médico de onde foram encaminhados ao hospital pelo médico ou outro profissional de saúde.

Entretanto, dentre as razões que os levaram àquele hospital, $17,4 \%$ buscaram o hospital por indicação de amigos e parentes, $11,0 \%$ porque 0 hospital tinha fama de confortável e ainda $9,7 \%$ porque ficava próximo de sua residência. Um pequeno número $(8,4 \%)$ procurou o hospital por razões financeiras, provavelmente aqueles atendidos em hospitais públicos ou filantrópicos.

As razóes apontadas nos sugerem que mesmo aqueles pacientes que passaram por outro serviço de saúde, pelo que a pesquisa evidenciou, também não se acham preparados para esclarecer e orientar corretamente outros pacientes.

Por outro lado, na grande maioria dos casos, não se identificou, entre os papéis exigidos para a internação, a guia de referência. Isto nos faz suspeitar de que os agentes de serviços de saúde năo dăo a devida importância ao sistema de referência ou năo săo suficientemente informados sobre a hierarquização dos serviços.

Nem mesmo o tipo de serviço que o hospital oferece é de conhecimento da maioria $(61,3 \%)$. Dentre os $38,7 \%$ que afirmam ter algum conhecimento sobre o hospital, $31,1 \%$ já estiveram internados ali. Menos da metade dos pacientes tinha conhecimento da competência profissional do pessoal do hospital e das condiçőes de atendimento.

A falta de orientação e o desconhecimento tanto dos agentes quanto dos usuários geram contradiçōes e obstaculizam inevitavelmente a adequação dos recursos e o funcionamento do sistema.

Se a informação é imprescindível ao bom funcionamento da organização, ela é também relevante para o usuário na sua condiçăo de enfermo. Para Heller ${ }^{(22)}$, o paciente carece sobre tudo de confiança, mais do que de piedade. Ele precisa ser informado e motivado sobre o cuidado que deve receber. "Isto lhe dará confiança durante o tratamento e ele cuidará de segui-lo da melhor maneira" (23).

Pode-se concluir, portanto, que conhecer o funcionamento da rede de serviços é impres-

22. HELLER, John R. "What does the patient understand as Comprehensive Health Care?" In: $A r$ chives of Physical Medicine and Rehabilitation. New York, vol 50, oct., 1969.

23. Idem, ibidem, pp. 563-565. 
cindível para atuar e caminhar dentro dela. E até mesmo por uma questão de justiça e solidariedade, $a$ informação deve ser divulgada.

A regionalização é outra categoria importante do modelo de organização sistêmica dos serviços de saúde, do ponto de vista da racionalização e distribuição de recursos. Interfere diretamente sobre a sistemática da demanda, o que procuramos verificar ao reconstruir a trajetória do paciente. Tornou-se importante, por isso, estabelecer as relaçőes entre a distribuição espacial dos serviços (no caso, dos hospitais) e o domicílio do paciente atendido, além da relação número de hospitais por população regional.

Os dados da pesquisa refletiram a concentração de hospitais na Regiaxo Centro de Belo Horizonte, com excessiva concentração do atendimento hospitalar nessa região.

É a Região Central da cidade que absorve a maior demanda, pois aí se localizam os hospitais mais altamente especializados; as demais regiōes, embora contem também com número de hospitais superior ao padrão teórico, têm demanda bem inferior.

Em decorrência da prática da referência e contra referência ser pouco freqüente em Belo Horizonte, o previdenciário se dirige preferencialmente aos níveis secundários de atendimento, 0 que evidentemente desestimula a sistematização da demanda.

Considerando que a regionalização implica a descentralização do atendimento de forma hierarquizada, apesar de a distribuição espacial dos serviços hospitalares em Belo Horizonte ser relativamente descentralizada, năo se tem aí atingido os objetivos da regionalização.

A efetiva descentralização do atendimento deverá implicar maiores esclarecimentos aos profissionais de saúde e à população sobre as condiçбes do atendimento, dando ênfase à prática da referência.

Se é certo que uma proposta de regionalização e hierarquização só se pode realizar quando todos os níveis de atenção estiverem intimamente relacionados, é evidente que a ausência do processo de informação, ainda que restrito à prática de encaminhamento, torna o sistema, no mínimo, instável.

A população não é informada sobre as condiçóes de funcionamento do sistema. Não se constataram canais formais de informação sobre a utilização dos serviços para os usuários.

Ao desinteresse e despreparo dos agentes quanto às normas de funcionamento da rede em Belo Horizonte, junta-se o descompromisso da intervenção estatal com as reais necessidades da população e a ausência de informações que facilitem a trajetória do paciente concretizando a implantação do sistema e a conseqüente utilização adequada dos recursos.

\section{CONCLUSÃO}

Pode-se concluir, pelos dados da pesquisa que fundamentou este trabalho, que realmente ocorre em Belo Horizonte uma distorção da demanda com relação aos objetivos de hierarquização e regionalização.

Comprovou-se que o sistema não provê a população de dados necessários à utilização adequada dos serviços e nem mesmo os agentes de saúde estão preparados para a função de informar e divulgar as normas de funcionamento da rede hierarquizada.

Ora, se aqueles a quem mais interessa o funcionamento correto do sistema năo é dado conhecer e, conseqüentemente, avaliar a prática da organização, que garantias existem para a implantação do mesmo?

A superação da atual forma de organização descoordenada por outra que institua uma administração pública sobre todas as instituiçסes, direta ou indiretamente relacionadas ao setor público e com todas as suas atividades integradas no sentido de dar respostas, de forma organizada, às necessidades prioritárias da população, requer, entre outras medidas, a participação popular e a preparação adequada dos recursos humanos para o desempenho de suas funções na condução do processo.

Tudo isso só será possível se se fizer um esforço de homogeneização do entendimento correto do significado da proposta e sua difusão. Fica claro, portanto, que qualquer mudança implicará necessariamente o esclarecimento não só dos profissionais de saúde, mas também e principalmente da população.

O reconhecimento da saúde como direito de cidadania e dever do Estado implica, na prática, reconhecer o seu caráter de serviço público e o papel do Estado no exercício da administração pública.

Isso significa que caberá ao Estado atuar sobre - Sistema Nacional de Saúde - incluindo os setores filantrópicos e privados - de modo a recolocá-lo no exercício da substancialidade de seus objetivos, a saber, a melhoria das condiçōes sanitárias da população.

Há que se considerar que a reformulação do Sistema Nacional de Saúde, conforme proposta pela $8^{\mathbf{a}}$ Conferência Nacional de Saúde, requer não só a reordenação de um sistema plural, habitado por inúmeros conflitos de interesses e por diferenciadas demandas de necessidades, mas também a ação no sentido de redirecioná-lo para o cumprimento de suas reais finalidades, o 
que só será possível com o apoio e a participação consciente da população.

De acordo com Paim, "a transparência dos aparelhos do Estado d̀ informação do público, o conhecimento público dos serviços estatais $e$ a administração pública das instituições (mesmo privadas) é que poderão contracenar com os riscos do 'estatismo autoritário' ou da 'democracia autoritária'" (24).

Deve-se guardar a clareza de que o processo de reformulação e redirecionamento do sistema, tendo em vista as reais necessidades da população, é um processo de construção social, de luta política e que requer, por isso mesmo, a definição de uma estratégia de implementação de projetos com um sentido préestabelecido (25).

Como bem nos lembra esse autor, "agir estrategicamente exige o abandono de uma atitude puramente normatioa que pressupõe que, pelos conteúdos de racionalidade ou de justiça social que uma proposta de reformulação contenha, ela garanta "a priori' sua viabilização" (26).

Para fugir a uma posição ingênua deve-se ter claro que, qualquer proposta de mudança, por mais democrática que seja, sofrerá antagonismos de grupos que terão seus interesses contrariados.

Será, pois, preciso usar a imaginação política, alimentada pela participação popular no sentido de "um movimento que simultaneamente acumule poder $e$, gradativamente, permita a realização de transformaçōes democratizadoras que irão colocar a saúde como direito de cidadania $e$ dever do Estado" (27).

Nesse sentido, ao questionar a operacionalização do SNS - Sistema Nacional de Saúde acredita-se que precedendo as mudanças estruturais há uma série de acertos internos à organização dos serviços que precisam ser tentados. São muitas vezes as providências de cunho administrativo destinadas a aumentar a eficiência e a eficácia na utilização dos recursos, através de uma comunicação mais estreita entre o sistema e o usuário, tendo em vista o papel do paciente na determinação de sua trajetória dentro da rede de prestação de serviços de assistência médica como fator de melhor atendimento às necessidades da população.

Para adquirir a consciência de seu direito à saúde, a população brasileira deverá exercitar uma prática consciente na utilização dos serviços de assistência médica, de tal modo que a consciência da prática se desenvolva no sentido de instrumentalizar a praxis política renovadora indispensável à conquista dos direitos sociais.

Isto posto, convém ressaltar que a informação assume relevância estratégica na reformulação do Sistema Nacional de Saúde.

Em primeiro lugar, porque um fluxo de informaçốes corretas entre as várias partes da organização sistêmica é condição de eficácia do sistema; e em segundo lugar, porque somente a partir do conhecimento sobre a utilização adequada dos serviços poderá a população dirigir-se à organização de forma consciente e exercer o seu direito à assistência médica para fazer reivindicaçoes específicas.

Entretanto, o caráter mais importante do processo de informação é de ser instrumento de conscientização sobre a realidade de saúde, capaz de desenvolver uma opinião pública com vistas à superação da atual situação sanitária da sociedade brasileira, em direção ao conceito ampliado de saúde.

Nunca é demais reafirmar a proposta do discurso inaugural da Organização Mundial de Saúde, em 1945: "Uma opinião pública bem informada e uma cooperação ativa por parte do público são de importancia capital para a melhoria de saúde do povo" (28).

Torna-se, pois, imprescindível que os profissionais e agentes de saúde sejam devidamente conscientizados da importância da informação correta e atualizada para a eficácia do sistema.

Para garantir a qualidade da informação sobre os serviços há que se preparar os agentes com relação ao funcionamento e aos objetivos do sistema.

Para que a população tenha acesso ao conhecimento necessário para a utilização adequada dos serviços de saúde, a comunicação deve se pautar pela clareza e objetividade.

Os postos de saúde devem ser também postos de informação capacitados a orientar e esclarecer a população sobre os serviços. $\square$

24. PAIM, Jairnilson Silva. Direito a Saúde, Cidadania e Estado. 8* Conferência Nacional de Saude, Rio de Janeiro, 1986, p. 25 (mimeo).

25. VILLAÇA MENDES, Eugênio. Reordenamento do Sistema Nacional de Saúde. 8* Conferência Nacional de Saúde, Rio de Janeiro, 1986 (mimeo).

26. Idem, ibidem, p. 35.

27. Idem, ibidem, p. 36

28. ORGANIZAÇÃO PANAMERICANA DE SAÚDE. Discossiones Técnicas de la XXII Reunión del Consejo Directivo de la O.P.S. Boletín de la Oficina Sanitaria Panamericana, Washington, 1974, p. 01. 